\title{
Indirect exclusion of four candidate genes for generalized progressive retinal atrophy in several breeds of dogs
} Tanja Lippmann, Sandra M Pasternack, Britta Kraczyk, Sabine E Dudek and Gabriele Dekomien*

Address: Human Genetics, Ruhr-University Bochum, Germany

Email: Tanja Lippmann - tanja.lippmann@t-online.de; Sandra M Pasternack - sandra.pasternack@ukb.uni-bonn.de; Britta Kraczyk - brittakraczyk@aol.com; Sabine E Dudek - sabineevad@aol.com; Gabriele Dekomien* - gabriele.dekomien@rub.de

* Corresponding author

Published: 29 November 2006

Journal of Negative Results in BioMedicine 2006, 5:19 doi:10.1 186/1477-5751-5-19

This article is available from: http://www.jnrbm.com/content/5/1/19

(c) 2006 Lippmann et al; licensee BioMed Central Ltd.

This is an Open Access article distributed under the terms of the Creative Commons Attribution License (http://creativecommons.org/licenses/by/2.0), which permits unrestricted use, distribution, and reproduction in any medium, provided the original work is properly cited.
Received: 19 June 2006

Accepted: 29 November 2006

\begin{abstract}
Background: Generalized progressive retinal atrophy (gPRA) is a hereditary ocular disorder with progressive photoreceptor degeneration in dogs. Four retina-specific genes, ATP binding cassette transporter retina (ABCA4), connexin 36 (CX36), c-mer tyrosin kinase receptor (MERTK) and photoreceptor cell retinol dehydrogenase $(R D H I 2)$ were investigated in order to identify mutations leading to autosomal recessive (ar) gPRA in 29 breeds of dogs.
\end{abstract}

Results: Mutation screening was performed initially by PCR and single strand conformation polymorphism (SSCP) analysis, representing a simple method with comparatively high reliability for identification of sequence variations in many samples. Conspicuous banding patterns were analyzed via sequence analyses in order to detect the underlying nucleotide variations. No pathogenetically relevant mutations were detected in the genes ABCA4, CX36, MERTK and RDHI2 in 71 affected dogs of 29 breeds. Yet 30 new sequence variations were identified, both, in the coding regions and intronic sequences. Many of the sequence variations were in heterozygous state in affected dogs.

Conclusion: Based on the ar transmittance of gPRA in the breeds investigated, informative sequence variations provide evidence allowing indirect exclusion of pathogenetic mutations in the genes ABCA4 (for 9 breeds), CX36 (for 12 breeds), MERTK (for all 29 breeds) and RDHI 2 (for 9 breeds).

\section{Background}

Single strand conformation polymorphism (SSCP) analysis is a simple and cost-effective method with high reliability for the identification of base substitutions or other sequence variations like small deletions or insertions in large cohorts of individuals [1]. We used SSCP analyses in order to define genetic alterations causing generalized progressive retinal atrophy (gPRA) in dogs. gPRA, like retinitis pigmentosa (RP) in man, represents a genetically heterogeneous disorder [2]. Usually, gPRA starts with night blindness and continues with restrictions in the vis- ual field. The final stage of disease is typically complete blindness. In different dog breeds, different ages at onset are observed as well as variable rates of disease progression [2,3]. Generally, gPRA is inherited in an autosomal recessive (ar) manner. Until now, causal mutations for ar gPRA have been identified exclusively in few dog breeds [3-7]. On the other hand, a number of photoreceptor genes have been excluded as the primary genetic cause of the trait in up to 26 dog breeds [8-15] investigated here. 
In this study we investigated four retina-specific genes, ATP binding cassette transporter retina (ABCA4), connexin 36 (CX36), c-mer tyrosin kinase receptor (MERTK) and photoreceptor cell retinol dehydrogenase (RDH12) for mutations leading to ar gPRA in 29 breeds of dogs. The $A B C A 4$ gene encodes the ABCR or RIM protein (RmP), thought to act as a flippase for $\mathrm{N}$-retinylidene phosphatidylethanolamine (N-retinylidene-PE), thereby facilitating the transport of all-trans-retinal from the disk lumen to the photoreceptor cytoplasm $[16,17]$. Mutations in the ABCA4 gene have been associated with ar transmitted Stargardt disease (STGD1), ar inherited cone-rod dystrophy (CRD) and ar RP [18-25]. CX36 gap junction channels are responsible for distinct coupling patterns of ganglion cells in inter- and output-neurons of the retina [26] and are essential for normal synaptic transmission within the rod pathway. In CX36-deficient mice the bwave of the electroretinogram is primarily affected, suggesting that CX36 is involved in the pathways generating the b-wave [27]. Furthermore, the MERTK gene encodes a receptor tyrosine kinase known as MER. The retinal pigment epithelium is the major site of MERTK expression in the retina. In a certain rat strain (Royal College of Surgeons, RCS) a small deletion in this gene leads to retinal degeneration [28]. Finally, RDH12 protein is involved in the production of 11-cis-retinal from 11-cis-retinol during regeneration of the cone visual pigments [29]. Mutations in the encoding gene $\mathrm{RDH} 12$ cause childhood-onset severe retinal dystrophy [30].

We describe here the mutation screening results in four canine retina-specific genes by SSCP analysis and DNA sequencing in 29 breeds of dogs. In addition, we use identified single nucleotide polymorphisms (SNP) for indirect exclusion of respective candidate genes in the analyzed pure-bred populations (based on the fact of 'founder effect' and inbreeding) for ar transmitted gPRA.

\section{Results and discussion}

We analyzed 71 unrelated dogs with an established clinical diagnosis of gPRA as well as 13 unaffected controls. In order to detect mutations in the ABCA4, CX36, MERTK or RDH12 genes we performed pre-screening by SSCP of genomic DNA and DNA sequencing for all band shifts detected. No pathogenetically relevant mutations were identified in the analyzed breeds of dogs. But we observed several polymorphisms, both, in the coding regions and intronic sequences, in the analyzed DNAs as summarized in see Additional file 1. These DNA sequence variations can be used as intra-genic markers, thus excluding segregation with ar gPRA. According to the breeding history ('founder effect' base on small numbers of dogs that were used to start the breed) and small population size of most breeds investigated, exclusively a single disease causing mutation is expected per breed. Furthermore, breeding histories point to few meiotic events, in which intra-genic recombinations could have occurred between an unidentified mutation in the gene locus in gPRA dogs and the investigated polymorphism. Animals affected by an ar transmitted trait are expected to be typed homozygously not only for the disease causing mutation but also for tightly linked non-pathogenic DNA sequence variations in the same gene. For that reason a polymorphism in heterozygous state in an affected dog will practically exclude mutations in the analyzed candidate gene as being implicated in the retinal disorder in a defined breed $[12,31]$.

The $A B C A 4$ gene consists of 47 exons. In addition to exons $2,3,6,9-10,12-13,21-22,28-29,34-35,39-40$ and $45-47$, whenever possible the conserved splice sites were also screened for sequence variations. The other exons were not examined, because we have detected many informative sequence variations in the analyzed parts of the ABCA4 gene which allowed indirect gene analysis. Altogether, we identified 18 SNP, 5 within exons 6,13 and 29 as well as 13 SNP within introns $6,9,21,28,45$ and 46 [see Additional file 1]. The SNP were present in heterozygous state in affected dogs in 18 of the 24 investigated breeds. With respect to the abovementioned background, the ABCA4 gene represents an exceptional case, because the gene spans a large genomic region of $150 \mathrm{~kb}$. Therefore, recombination events have to be taken into account for this gene between a hypothetical unidentified mutation and the investigated SNP. Consequently, indirect exclusion of this candidate gene is only possible for those breeds for which affected dogs are typed heterozygous for polymorphisms in the $5^{\prime}$ and the $3^{\prime}$ parts of the gene. Under this conservative precondition, we excluded mutation in the $A B C A 4$ gene as a cause for gPRA in the breeds Berger des Pyrénées, Kucasz, Lowchens, Saarloos, Salukis, Scottish Terriers, Schapendoes, Sloughis and Tibetan Terriers.

During SSCP analysis of the 2 exons (and adjacent intron/ exon boundaries) of the CX36 gene, two SNP were identified within the ORF, both not causing amino acid exchanges. The c.621T>C transversion was identified only in Afghan Hounds and Salukis; the c.678A $>$ G variation occurs in 16 breeds [see Additional file 1]. In 11 of the 24 investigated breeds this sequence variation was found in heterozygous state in gPRA-affected dogs. Because of the small size of the gene and the above described reasoning, CX36 mutations can be excluded as the cause of gPRA within Airedale Terriers, Afghan Hound, Conton de Tulears, Dachshunds, Kuvasz, Lowchens, Miniature Poodles, Saarloos, Salukis, Scottish Terriers, Sloughis and Tibetan Terriers.

The MERTK gene was examined here for polymorphisms in 29 breeds by PCR-SSCP analysis of exons 4, 6-8 and 10 
including splice donor and acceptor sites as well as adjacent intronic sequences. Because seven single base substitutions were identified in all analyzed exons as well as one SNP in intron 7, we did not investigate the MERTK gene any further. Our typing results suggest the sequence variations in the MERTK gene are not causative for gPRA in all 29 analyzed breeds [see Additional file 1].

In the seven exons of the RDH12 gene (including all intronic splice signal sequences), two sequence variations were obvious: an infrequent by observed sequence exchange in exon 1 and a more common SNP in intron 4 [see Additional file 1]. Since diseased animals were heterozygous for the polymorphism in intron 4 , the RDH12 gene is very unlikely to harbor any critical mutation causing gPRA in the following breeds: Airedale Terriers, Conton de Tulears, Glen of Imaal Terriers, Giant Schnauzers, Golden Retrievers, Kuvasz, Lowchen, Miniature Poodles and Dachshunds.

In 16 of the investigated dog breeds exclusively one gPRA affected animal was available for mutation analysis [see Table 1]. For these breeds an exclusion of the investigated genes is not regarded as being definitive. Altogether, the mutation screening of the four genes performed by SSCP analysis revealed 30 new SNP. This fact underscores that SSCP screening is still a quite useful, sensitive [1] and costeffective method as of today, especially for a large number of DNA samples. The newly identified SNP were used for exclusion of the four investigated candidate genes in canine eye disease for a large number of analyzed breeds. In addition, the identified SNP in the ABCA4, CX36, MERTK and RDH12 genes occurred in several breeds, rendering them useful markers for future studies.

\section{Conclusion}

Mutation screening for gPRA in four canine retina-specific genes (ABCA4, CX36, MERTK and RDH12 gene) was performed by SSCP analysis and DNA sequencing. Even though no pathogenetically relevant mutations were detected in 71 affected dogs of 29 breeds, 30 new sequence variations were identified. These single nucleotide polymorphisms were subsequently used for indirect exclusion of the 4 candidate genes for autosomal recessively transmitted gPRA in the analyzed pure-bred populations (based on the fact of 'founder effect' and inbreeding). Using this approach, the indirect exclusion of pathogenetic mutations in the $A B C A 4$ gene was possible for 9 breeds, in the CX36 gene for 12 breeds, in MERTK for all 29 breeds and in RDH12 for 9 breeds.

\section{Materials and methods}

Blood from 84 dogs of 29 different breeds, including 71 gPRA-affected animals [see Table 1] was collected with the permission of the owner and in cooperation with breed- ing organizations. For two of these breeds the causative gPRA mutations are already known (Sloughi: [7]; Miniature Poodles: patented by OptiGen). These breeds were included as controls for the analysis of possibly found potential mutations.

In some cases a dominant inheritance of gPRA or misdiagnosis of gPRA due to phenocopies might be theoretically possible, but the performed pedigree analyses (data not shown) suggest that ar inheritance prevails on all accounts in the breeds analyzed here. The pedigree analyses also show, that the affected dogs of the breeds for which several samples were available were closely related. This could strengthen the assumption that within these breeds each gPRA affected dog has the same causal mutation. Experienced veterinarians confirmed the gPRA status of affected and unaffected dogs by ophthalmoscopy as documented in certificates of the eye examinations. Genomic DNA was extracted from peripheral blood according to standard protocols [32].

Parts of the ABCA4 gene were cloned from a genomic canine $\lambda$-DNA library ( $\lambda$ FIX II Library; host: $E$. coli XL1Blu MRA (P2) Stratagene, La Jolla, CA, USA) according to the Stratagene standard protocol and described in detail elsewhere [10]. In order to characterize the flanking introns of exon 3 and 6 of the $A B C A 4$ gene one isolated $\lambda$ clone was directly sequenced with exonic primers specific for exons 3 and 6 . The other exon/intron boundaries of the $A B C A 4$ gene were analyzed by comparing the mRNA sequence of the canine gene (EMBL accession number AJ784316) to the genomic sequence of the human gene (EMBL accession number AF001945). For SSCP analyses DNA sequences of exons $2,3,6,9-10,12-13,21-22,28-$ $29,34-35,39-40$ and $45-47$ of the $A B C A 4$ gene were amplified including adjacent intervening sequences [see Additional file 2].

The canine CX36 gene was characterized by sequencing genomic DNA with exonic 'human' primers in conserved regions of the gene. The exon/intron boundaries were analyzed by comparison of this canine genomic sequence with mRNA sequence of the human CX36 gene (EMBL accession number NM_020660.1). For SSCP analyses DNA sequences of exon 1 and 2 of the CX36 gene were amplified by overlapping PCRs including neighboring intronic sequences [see Additional file 2].

Genomic sequence and exon/intron boundaries of MERTK and RDH12 genes were determined from dog genome databases (UCSC Genome Bioinformatics website, dog genome sequence as of May 2005) by searching with the human mRNA of the two genes (MERTK: EMBL accession number U08023.1; RDH12: EMBL accession number BC025724.1). Exons 4, 6-8 and 10 of the MERTK 
Table I: Dog breeds examined for gPRA causing mutations.

\begin{tabular}{|c|c|c|}
\hline Breed (abbreviation) & Number of dogs investigated & gPRA-affected dogs \\
\hline Afghan Hound (AW) & I & I \\
\hline Airedale Terrier (AT) & 6 & 5 \\
\hline Akita Inu (Aki) & 2 & I \\
\hline Bearded Collie (BCo)* & 2 & 2 \\
\hline Berger des Pyrénées (BDP) & 2 & 1 \\
\hline Bichon Bolognese (Bo) & 1 & I \\
\hline Conton de Tulear (CdT) & 5 & 4 \\
\hline Curly-Coated Retriever (CCR) & 1 & 1 \\
\hline Flat-Coated Retriever (FCR)* & I & I \\
\hline Giant Schnauzer (GS) & I & I \\
\hline Glen of Imaal Terrier (GIT)* & 8 & 7 \\
\hline Golden Retriever (GR) & 3 & I \\
\hline Jack Russel Terrier (JRT) & 1 & I \\
\hline Kuvasz $(\mathrm{Ku})$ & 4 & 3 \\
\hline Lowchen (Lo) & 7 & 6 \\
\hline Miniature Poodle (MP) & 4 & 4 \\
\hline Newfoundlanddog (NF) & 1 & I \\
\hline Polish Lowland Sheepdog (PON) & I & I \\
\hline Rottweiler (Ro) & 1 & I \\
\hline Saarloos/Wolfshound (Sa) & 7 & 6 \\
\hline Saluki (Persian Greyhound; Sal) & 2 & I \\
\hline Schapendoes (Dutch Sheepdog; SD) & 5 & 4 \\
\hline Scottish Collie (Co) & 2 & 2 \\
\hline Scottish Terrier (ScT) & 1 & 1 \\
\hline Sloughi (Arabian Greyhound; SI) & 3 & 2 \\
\hline Standard Schnauzer (SS)* & 1 & I \\
\hline Tibetan Terrier (TT) & 4 & 4 \\
\hline Wire-haired Dachshund (WD) & 6 & 6 \\
\hline Yorkshire Terrier $(\mathrm{Y})^{*}$ & 1 & 1 \\
\hline Total & 84 & 71 \\
\hline
\end{tabular}

* Examined only for MERTK and RDHI 2 genes

gene and all 7 exons of the RDH12 gene were screened for mutations by SSCP analyses including flanking intron sequences [see Additional file 2].

All PCRs were performed under standard PCR conditions [10-12] in a thermocycler (Biometra, Goettingen, Germany) with Taq Polymerase (Genecraft, Münster, Germany) and varying concentrations of $\mathrm{MgCl}_{2}$ [see Additional file 2]. For SSCP analyses, $0.06 \mu \mathrm{l}$ of [ $\left.\alpha^{32} \mathrm{P}\right]$ dCTP $(10 \mathrm{mCi} / \mathrm{ml})$ was included. PCR products were digested depending on the lengths of the fragments with different restriction enzymes [see Additional file 2] in order to optimize mutation screening by SSCP analysis [1]. Aliquots of the PCRs $(3 \mu \mathrm{l})$ were denatured with $7 \mu \mathrm{l}$ of loading buffer $(95 \%$ deionised formamide $10 \mathrm{mM}$ $\mathrm{NaOH}, 20 \mathrm{mM}$ EDTA, $0.06 \%(\mathrm{w} / \mathrm{v})$ xylene cyanol and $0.06 \%(\mathrm{w} / \mathrm{v})$ bromphenol blue). The samples were heated to $95^{\circ} \mathrm{C}$ for $5 \mathrm{~min}$ and snap cooled on ice. Aliquots $(3 \mu \mathrm{l})$ of the samples were separated in two sets of $6 \%$ polyacrylamide (acrylamide/bisacrylamide: 19/1) gels, one set with $10 \%$ glycerol, another containing $5 \%$ glycerol and 1 $\mathrm{M}$ urea. Gels were run with $1 \mathrm{X}$ TBE buffer at $30-50 \mathrm{~W}$ for $3-6 \mathrm{~h}$ at $4^{\circ} \mathrm{C}$, dried and analyzed by autoradiography. All DNA samples exhibiting band shifts as evidenced by SSCP electrophoresis were purified and cycle sequenced. Sequencing reactions were carried out by the dideoxy chain termination method using the Dyenamic ET Terminator Kit (Amersham Biosciences, Freiburg, Germany) according to the manufacturer's instructions and were run on an automated capillary DNA sequencer (MegaBACE 1000, Amersham Biosciences, Freiburg, Germany).

\section{Authors' contributions}

TL conceived the experimental outline, collected blood samples, conducted the experiments, analyzed the data and drafted the manuscript. SMP, BK and SED carried out parts of the experiments and were involved in analyzing the data. JTE and GD participated in design and coordination of the study and helped to draft the manuscript. All authors read and approved the final manuscript. 


\section{Additional material}

\section{Additional file 1}

Sequence variations in the ABCA4, CX36, MERTK and RDH12 genes in different dog breeds and indirect exclusion of the genes as causing gPRA, respectively. The data provided represent the results of the mutation screening of the candidate genes ABCA4, CX36, MERTK and RDH12. Click here for file

[http://www.biomedcentral.com/content/supplementary/14775751-5-19-S1.doc]

\section{Additional file 2}

Primers, conditions for PCR amplification and restriction enzymes used before SSCP analyses. The data provided represent the information for PCR amplification and restriction of PCR products which were used in SSCP analyses.

Click here for file

[http://www.biomedcentral.com/content/supplementary/14775751-5-19-S2.doc]

\section{Acknowledgements}

We thank the owners of the dogs for blood samples, the veterinarians of the Dortmunder Ophthalmologenkreis (DOK) for the ophthalmologic investigations of the dogs and for the support of different breeding clubs. These studies were supported by the Gesellschaft für kynologische Forschung, Bonn (Germany).

\section{References}

I. Jaeckel S, Epplen JT, Kauth M, Miterski B, Tschentscher F, Epplen C: Polymerase chain reaction-single strand conformation polymorphism or how to detect reliably and efficiently each sequence variation in many samples and many genes. Electrophoresis 1998, I9(18):3055-306I.

2. Clements PJ, Sargan DR, Gould DJ, Petersen-Jones SM: Recent advances in understanding the spectrum of canine generalised progressive retinal atrophy. I Small Anim Pract 1996, 37(4): I 55- I62.

3. Petersen-Jones SM, Entz DD, Sargan DR: cGMP phosphodiesterasealpha mutation causes progressive retinal atrophy in the Cardigan Welsh corgi dog. Invest Ophthalmol Vis Sci 1999, 40(8): $1637-1644$.

4. Suber ML, Pittler SJ, Qin N, Wright GC, Holcombe V, Lee RH, Craft CM, Lolley RN, Baehr W, Hurwitz RL: Irish setter dogs affected with $\mathrm{rod} /$ cone dysplasia contain a nonsense mutation in the rod cGMP phosphodiesterase beta-subunit gene. Proc Natl Acad Sci U S A 1993, 90(9):3968-3972.

5. Aguirre G: Genes and diseases in man and models. Prog Brain Res 200I, I 3 I:663-678.

6. Kijas JW, Cideciyan AV, Aleman TS, Pianta MJ, Pearce-Kelling SE, Miller B], Jacobson SG, Aguirre GD, Acland GM: Naturally occurring rhodopsin mutation in the dog causes retinal dysfunction and degeneration mimicking human dominant retinitis pigmentosa. Proc Natl Acad Sci U S A 2002, 99(9):6328-6333.

7. Dekomien G, Runte M, Godde R, Epplen JT: Generalized progressive retinal atrophy of Sloughi dogs is due to an 8-bp insertion in exon 21 of the PDE6B gene. Cytogenet Cell Genet 2000, 90(34):26I-267

8. Dekomien G, Epplen JT: Evaluation of the canine RPE65 gene in affected dogs with generalized progressive retinal atrophy. Mol Vis 2003, 9:60I-605.

9. Dekomien G, Epplen JT: Analysis of PDE6D and PDE6G genes for generalised progressive retinal atrophy (gPRA) mutations in dogs. Genet Sel Evol 2003, 35(4):445-456

10. Dekomien G, Epplen JT: The canine Recoverin (RCVI) gene: a candidate gene for generalized progressive retinal atrophy. Mol Vis 2002, 8:436-44I.

II. Dekomien G, Epplen JT: Screening of the arrestin gene in dogs afflicted with generalized progressive retinal atrophy. BMC Genet 2002, 3(I): 12 .

12. Dekomien G, Epplen JT: The canine Phosducin gene: characterization of the exon-intron structure and exclusion as a candidate gene for generalized progressive retinal atrophy in II dog breeds. Mol Vis 2002, 8: $138-142$

13. Dekomien G, Epplen JT: Exclusion of the PDE6A gene for generalised progressive retinal atrophy in II breeds of dog. Anim Genet 2000, 3 I (2): I35-139.

14. Klein W, Dekomien G, Holmes N, Epplen JT: Evaluation of ROMI as a candidate gene in generalised progressive retinal atrophy in dogs. Anim Genet 1998, 29(4):316-318

15. Runte M, Dekomien G, Epplen JT: Evaluation of RDS/Peripherin and $R O M I$ as candidate genes in generalised progressive retinal atrophy and exclusion of digenic inheritance. Anim Genet 2000, 3 I (3):223-227.

16. Azarian SM, Travis $\mathrm{GH}$ : The photoreceptor rim protein is an ABC transporter encoded by the gene for recessive Stargardt's disease (ABCR). FEBS Lett 1997, 409(2):247-252.

17. Weng J, Mata NL, Azarian SM, Tzekov RT, Birch DG, Travis GH: Insights into the function of Rim protein in photoreceptors and etiology of Stargardt's disease from the phenotype in abcr knockout mice. Cell 1999, 98(I):13-23.

18. Martinez-Mir A, Paloma E, Allikmets R, Ayuso C, del Rio T, Dean M, Vilageliu L, Gonzalez-Duarte R, Balcells S: Retinitis pigmentosa caused by a homozygous mutation in the Stargardt disease gene ABCR. Nat Genet 1998, I 8(I): I I-I2.

19. Shroyer NF, Lewis RA, Yatsenko AN, Lupski JR: Null missense ABCR (ABCA4) mutations in a family with stargardt disease and retinitis pigmentosa. Invest Ophthalmol Vis Sci 200I, 42(I 2):2757-276I.

20. Fukui T, Yamamoto S, Nakano K, Tsujikawa M, Morimura $\mathrm{H}$, Nishida $\mathrm{K}$, Ohguro N, Fujikado T, Irifune M, Kuniyoshi K, Okada AA, Hirakata A, Miyake $\mathrm{Y}$, Tano $\mathrm{Y}$ : ABCA4 gene mutations in Japanese patients with Stargardt disease and retinitis pigmentosa. Invest Ophthalmol Vis Sci 2002, 43(9):2819-2824.

21. Klevering BJ, Blankenagel A, Maugeri A, Cremers FP, Hoyng CB, Rohrschneider K: Phenotypic spectrum of autosomal recessive conerod dystrophies caused by mutations in the ABCA4 (ABCR) gene. Invest Ophthalmol Vis Sci 2002, 43(6): 1980-1985.

22. Paloma E, Coco R, Martinez-Mir A, Vilageliu L, Balcells S, GonzalezDuarte R: Analysis of ABCA4 in mixed Spanish families segregating different retinal dystrophies. Hum Mutat 2002, 20(6):476.

23. Rudolph G, Kalpadakis P, Haritoglou C, Rivera A, Weber BH: Mutations in the ABCA4 gene in a family with Stargardt's disease and retinitis pigmentosa (STGD I/RP I 9). Klin Monatsbl Augenheilkd 2002, $219(8): 590-596$.

24. Fishman GA Stone EM, Eliason DA, Taylor CM, Lindeman M, Derlack DJ: ABCA4 gene sequence variations in patients with autosomal recessive cone-rod dystrophy. Arch Ophthalmol 2003, I 2 I (6):85 I-855

25. Klevering BJ, Maugeri A, Wagner A, Go SL, Vink C, Cremers FP, Hoyng $\mathrm{CB}$ : Three families displaying the combination of Stargardt's disease with cone-rod dystrophy or retinitis pigmentosa. Ophthalmology 2004, I I I (3):546-553.

26. Schubert T, Degen J, Willecke K, Hormuzdi SG, Monyer H, Weiler R: Connexin 36 mediates gap junctional coupling of alpha-ganglion cells in mouse retina. J Comp Neurol 2005, 485(3): I9I-20I.

27. Guldenagel M, Ammermuller J, Feigenspan A, Teubner B, Degen J, Sohl $\mathrm{G}$, Willecke $\mathrm{K}$, Weiler R: Visual transmission deficits in mice with targeted disruption of the gap junction gene connexin36. J Neurosci 200I, 2 I ( I 6):6036-6044.

28. D'Cruz PM, Yasumura D, Weir J, Matthes MT, Abderrahim H, LaVail MM, Vollrath D: Mutation of the receptor tyrosine kinase gene Mertk in the retinal dystrophic RCS rat. Hum Mol Genet 2000, 9(4):645-65।

29. Haeseleer F, Jang GF, Imanishi Y, Driessen CA, Matsumura M, Nelson PS, Palczewski K: Dual-substrate specificity short chain retinol dehydrogenases from the vertebrate retina. J Biol Chem 2002 , 277(47):45537-45546.

30. Janecke AR, Thompson DA, Utermann G, Becker C, Hubner CA, Schmid E, McHenry CL, Nair AR, Ruschendorf F, Heckenlively J, Wissinger $B$, Nurnberg $\mathrm{P}, \mathrm{Gal} A$ : Mutations in RDH 12 encoding a photoreceptor cell retinol dehydrogenase cause childhood-onset severe retinal dystrophy. Nat Genet 2004, 36(8):850-854.

31. Aguirre-Hernandez J, Sargan DR: Evaluation of candidate genes in the absence of positional information: a poor bet on a blind dog! J Hered 2005, 96(5):475-484.

32. Miller SA, Dykes DD, Polesky HF: A simple salting out procedure for extracting DNA from human nucleated cells. Nucleic Acids Res 1988, 16(3): 1215. 